\title{
COMMUNICATION
}

\section{Laccase/TEMPO-mediated system for the thermodynamically disfavored oxidation of 2,2- dihalo-1-phenylethanol derivatives}

Cite this: DOI: $10.1039 / \times 0 \times x 00000 x$

Received 00th January 2014

Kinga Kędziora, Alba Díaz-Rodríguez, Iván Lavandera, Vicente GotorAccepted 00th January 2014 Fernández and Vicente Gotor*

DOI: $10.1039 / \times 0 \times x 00000 x$

www.rsc.org/

An efficient methodology to oxidize $\beta, \beta$-dihalogenated secondary alcohols employing oxygen was achieved in a biphasic medium using the laccase from Trametes versicolor/TEMPO pair, providing the corresponding ketones in a clean fashion under very mild conditions. Moreover, a chemoenzymatic protocol has been successfully applied to deracemize 2,2-dichloro-1-phenylethanol combining this oxidation with an alcohol dehydrogenase-catalyzed bioreduction.

Oxidation of alcohols into the corresponding carbonylic compounds is one of the fundamental reactions in organic chemistry. Traditionally these transformations comprised the use of hazardous metal-based reagents in stoichiometric amount, however catalytic methodologies employing oxygen (or air) as mild oxidant in aqueous medium are being recognized for large scale applications, and therefore they are currently emerging as potent competitors. ${ }^{1}$ From an economic and environmental point of view, these strategies are highly appealing since they produce water as the only by-product.

In this context, biological catalysts are gaining more relevance to perform oxidative processes, especially due to the mildness conditions and high selectivities displayed in these transformations. ${ }^{2}$ Among the different types of enzymes implicated in these reactions, oxidases have appeared as an interesting class since they use molecular oxygen as the electron acceptor. ${ }^{3}$ In particular laccases are multicopper biocatalysts present in many fungi, plants and bacteria, and are responsible for the reduction of $\mathrm{O}_{2}$ into $\mathrm{H}_{2} \mathrm{O}$ at the expense of the substrate oxidation. ${ }^{3 a, 4}$ Additionally, they are accessible and cheap compared to other reported metal complexes. Apart from that, laccases work efficiently in water as the natural medium, although they can also accept organic co-solvents, ${ }^{5}$ which can be highly desirable when dealing with hydrophobic derivatives. Phenolic compounds are their natural substrates, but laccases have shown to be also effective towards primary alcohols or amines making use of, e.g. ABTS, benzotriazole, or syringaldehyde, among others. ${ }^{6}$ One of the most employed is (2,2,6,6-tetramethylpiperidin-1-yl)oxy (TEMPO) due to its accessibility and high compatibility with this class of enzyme. Recently, this laccase/TEMPO catalytic system has been reported as a potent alternative to chemoselectively oxidize benzylic and primary alcohols over secondary ones. ${ }^{7}$

Especially challenging is the oxidation of alcohols substituted at $\beta$ position with electron-withdrawing groups (EWG), e.g. halohydrins. To date, Dess-Martin periodinane, ${ }^{8}$ ruthenium $^{9}$ and iridium-based ${ }^{10}$ catalysts, Swern, ${ }^{11}$ tetrapropylammonium perruthenate (TPAP), ${ }^{11,12}$ and Jones' reagent ${ }^{13}$ have been reported for the oxidation of this type of substrates. Owing to their high reactivity, $\alpha, \alpha$-dihalogenated ketones are versatile building blocks for the synthesis of, among others, mandelic acid, ${ }^{14}$ oxazines, ${ }^{15}$ triazines, ${ }^{16} \alpha, \beta$-unsaturated ketones, ${ }^{17}$ and triazole derivatives. ${ }^{18}$ In the course of our investigations on biocatalyzed redox processes, it was observed that the oxidation of halohydrins was hardly feasible under alcohol dehydrogenase (ADH)catalyzed hydrogen transfer conditions. ${ }^{19}$ Following this study and based on our previous experience on the selective oxidation of alcohols using Trametes versicolor laccase and TEMPO, ${ }^{\text {7a }}$ we have explored this catalytic system in the disfavored oxidation of secondary alcohols 1a-i.<smiles>[R]c1ccc(C(O)C([X])Cl)cc1</smiles>

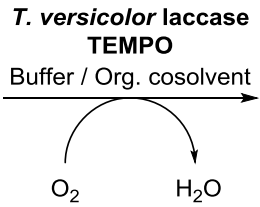<smiles>[R]c1ccc(C(=O)C([X])Cl)cc1</smiles>

a, $\mathrm{R}=\mathrm{H}, \mathrm{X}=\mathrm{Cl} ; \mathbf{b}, \mathrm{R}=o-\mathrm{Cl}, \mathrm{X}=\mathrm{Cl} ; \mathbf{c}, \mathrm{R}=m-\mathrm{Cl}, \mathrm{X}=\mathrm{Cl}$ d, $\mathrm{R}=p-\mathrm{Cl}, \mathrm{X}=\mathrm{Cl} ; \mathbf{e}, \mathrm{R}=m-\mathrm{OMe}, \mathrm{X}=\mathrm{Cl} ; \mathbf{f}, \mathrm{R}=m-\mathrm{NO}_{2}, \mathrm{X}=\mathrm{Cl}$ g, $R=H, X=B r ; h, R=H, X=F ; i, R=H, X=H$

Scheme 1 General methodology to synthesize $\alpha, \alpha$-dihalogenated acetophenone derivatives $\mathbf{2} \mathbf{a}-\mathbf{h}$ and 2 -chloroacetophenone (2i) through oxidation reactions with the laccase/TEMPO system. 
Since the laccase/mediator system is able to oxidize primary and secondary benzylic alcohols, ${ }^{7 b, d, 20}$ we reasoned that laccase/TEMPO could also lead to carbonylic compounds bearing electron-withdrawing groups at $\alpha$-position under aerobic conditions. Therefore, several 2,2dihalogenated 1-phenylethanol derivatives (1a-h) and 2-chloro-1phenylethanol 1i (Scheme 1) were synthesized, and these compounds were tested as possible substrates.

In a first set of experiments, the influence of the oxygenation was investigated. ${ }^{21}$ Thus, the oxidation of 2,2-dichloro-1-phenylethanol (1a, $0.1 \mathrm{mmol}, 50 \mathrm{mM}$ ) as model substrate was performed in a $50 \mathrm{mM}$ sodium acetate ( $\mathrm{NaOAc}$ ) buffer $\mathrm{pH} 4.5$ at $30^{\circ} \mathrm{C}$ and $20 \% \mathrm{~mol}$ of TEMPO under two different conditions: a) opening the reaction mixture to ambient air; and b) bubbling oxygen in the vessel with a balloon. Remarkably, while for the first case a conversion of $33 \%$ was attained after $24 \mathrm{~h}$, the second protocol led to a $53 \%$ of ketone $2 \mathrm{a}$. The reactions were carried out using a $10 \% \mathrm{v} / \mathrm{v}$ of acetonitrile (MeCN) as a result of the low solubility of 1a. Although still conversions were not quantitative, we observed that this method was able to smoothly afford the final compound, avoiding the formation of undesired byproducts. Therefore, the reaction conditions bubbling oxygen were chosen for further optimizations. Other parameters such as temperature $\left(20-40^{\circ} \mathrm{C}\right)$, TEMPO equivalents (20-40\% mol), or $\mathrm{pH}$ (3.56.0) were also examined, without finding significant improvements (see ESI).

Next, we decided to study the effect of the organic co-solvent by adding water miscible and non-miscible co-solvents, giving rise to mono- or biphasic systems. The addition of organic co-solvents can improve the solubility of hydrophobic substrates and the stability of this catalytic method as observed for similar transformations. ${ }^{22}$ To minimize mass transfer issues, a gentle magnetic stirring was performed in all cases. Thus, dimethylsulfoxide (DMSO) and MeCN were studied as additives in monophasic mixtures while dichloromethane, toluene and methyl tert-butyl ether (MTBE) were added to form biphasic systems (see ESI). Among them, MeCN, toluene and MTBE afforded the best oxidation conversions (56-70\%), so further studies were developed with these organic solvents.

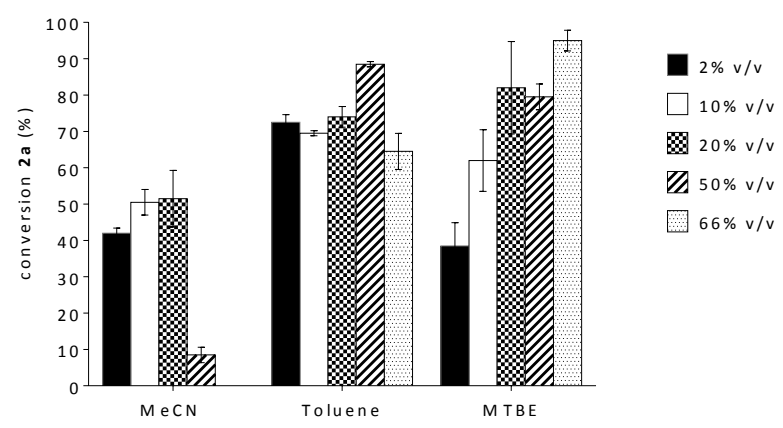

Fig. 1 Effect of the organic co-solvent concentration in the $T$. versicolor laccase/TEMPO $(20 \% \mathrm{~mol})$ system to oxidize alcohol 1 a $(50 \mathrm{mM})$ into $2 \mathrm{a}$, bubbling oxygen in a $50 \mathrm{mM} \mathrm{NaOAc}$ buffer pH 4.5 at $20^{\circ} \mathrm{C}$ (toluene and MTBE) or $30{ }^{\circ} \mathrm{C}(\mathrm{MeCN})$ after $24 \mathrm{~h}$.

Hence, the effect of the concentration of these organic co-solvents was studied with respect to the NaOAc buffer (2-66\% v/v, Figure 1). Due to the low boiling point of MTBE, the reactions with this solvent were carried out at $20{ }^{\circ} \mathrm{C}$, and therefore, this was also the temperature of choice for the other non-miscible solvent (toluene), while the oxidations with water-miscible $\mathrm{MeCN}$ were performed at 30 ${ }^{\circ} \mathrm{C}$. In this case, it remained clear that percentages higher than $20 \% \mathrm{v} / \mathrm{v}$ inhibited the laccase/TEMPO system while non-miscible solvents could be employed in larger amounts. Especially with MTBE, excellent conversions were achieved after $24 \mathrm{~h}(95 \%)$, showing that the addition of this organic co-solvent displayed a positive influence on the oxidation of 1a. In addition, following the guidelines of greener alternatives for chlorinated or diethyl ether solvents, MTBE appeared as the one of the best options for an immiscible organic co-solvent. ${ }^{23}$ We also studied the use of a lower amount of TEMPO equivalents (5$10 \% \mathrm{~mol}$ ), but conversions were incomplete (51-85\%).

The continuous oxygen bubbling process evaporated the organic solvent after a short period of time (2-3 h). Overall, it can be considered that this oxidation was accomplished at the end in aqueous medium. To investigate the possible effect of MTBE in this reaction, we followed the oxidation of 1a within the time (Figure 2), with and without the presence of MTBE. While a conversion of nearly $50 \%$ into 2a was achieved in the first $3 \mathrm{~h}$ for the biphasic system, less than $10 \%$ conversion was detected for the solely aqueous system. ${ }^{24}$ The positive effect of MTBE seems to be more related to an improvement of the substrate solubility than with the TEMPO stability, as conversions in plain buffer were continuously increasing at comparable rates after 4 h. Similar positive properties have already been described for other water-organic media employing a laccase with a chemical mediator. ${ }^{22}$

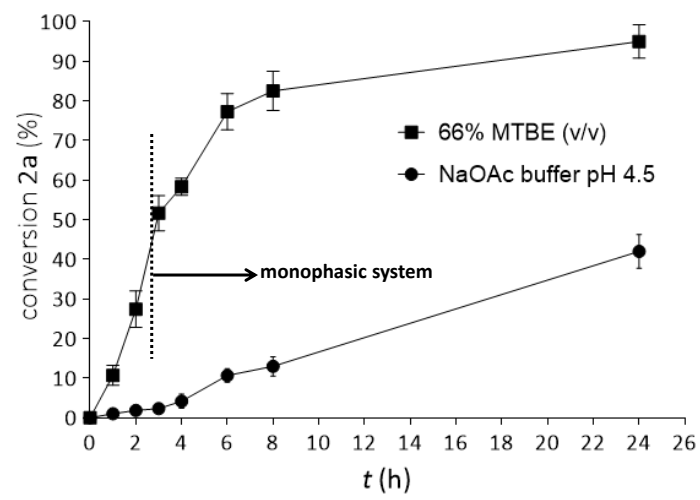

Fig. 2 Reaction course of the T. versicolor laccase/TEMPO (20\% mol) system to oxidize alcohol 1a (50 $\mathrm{mM}$ ) into 2 a, bubbling oxygen in a $50 \mathrm{mM}$ NaOAc buffer $\mathrm{pH} 4.5$ at $20^{\circ} \mathrm{C}$ in the presence of MTBE (66\% v/v). After 2-3 h, it was observed the disappearance of the organic solvent.

Having found appropriate conditions to oxidize alcohol 1a (Table 1, entry 1 ), the scope of this transformation was expanded to other dihalogenated derivatives $\mathbf{1} \mathbf{b}$-h. The system efficiency depended on the position of the phenyl ring substitution, observing high to excellent conversions for meta- or para-substituted compounds, while a very low formation of ketone $\mathbf{2} \mathbf{b}$ was found for the ortho-derived alcohol $\mathbf{1 b}$ (compare entries 2 to 4 ). On the other side, alcohols with differing electronic properties such as chlorine, methoxy or nitro were oxidized (entries 3-6). Additionally, substrates with other halogen atoms at $\alpha$ position such as bromine (entry 7) or fluorine (entry 8 ) also afforded the halogenated ketones with conversions higher than $75 \%$. It is remarkable that the desired carbonylic compounds were formed as 
the sole products, not detecting other derivatives in any case. When using the alcohol 1a, the substrate concentration could be increased up to $200 \mathrm{mM}$ obtaining a conversion of $93 \%$ after $24 \mathrm{~h}$. This is in line with other reports that have demonstrated the performance of laccases at high substrate concentrations. ${ }^{7 b, 25}$ Satisfyingly, some of these oxidative transformations could be easily performed at $100-\mathrm{mg}$ scale, isolating the corresponding ketones in very high yields (76-81\%, see ESI for more details).

Table 1 Oxidation of secondary alcohols 1 a-j using the laccase/TEMPO system $^{a}$

\begin{tabular}{|c|c|c|c|c|c|}
\hline & $\mathrm{OH}$ & \multicolumn{2}{|c|}{$\begin{array}{c}\text { T. versicolor laccase } \\
\text { TEMPO } \\
\begin{array}{c}\text { Buffer / MTBE (1:2) } \\
20^{\circ} \mathrm{C} / 24 \mathrm{~h}\end{array}\end{array}$} & \multicolumn{2}{|c|}{$2 a-j$} \\
\hline Entry & Alcohol & $\mathrm{R}$ & $x$ & $\mathrm{Y}$ & $2 \mathrm{a}-\mathrm{j}(\%)^{b}$ \\
\hline 1 & $1 a$ & $\mathrm{H}$ & $\mathrm{Cl}$ & $\mathrm{Cl}$ & $95 \pm 2.8$ \\
\hline 2 & $1 \mathrm{~b}$ & $o-\mathrm{Cl}$ & $\mathrm{Cl}$ & $\mathrm{Cl}$ & $4 \pm 1.4$ \\
\hline 3 & $1 c$ & $m-\mathrm{Cl}$ & $\mathrm{Cl}$ & $\mathrm{Cl}$ & $78 \pm 3.5$ \\
\hline 4 & 1d & $p-\mathrm{Cl}$ & $\mathrm{Cl}$ & $\mathrm{Cl}$ & $91 \pm 2.1$ \\
\hline 5 & $1 e$ & $m$-OMe & $\mathrm{Cl}$ & $\mathrm{Cl}$ & $82 \pm 4.2$ \\
\hline 6 & $1 f$ & $m-\mathrm{NO}_{2}$ & $\mathrm{Cl}$ & $\mathrm{Cl}$ & $95 \pm 4.2$ \\
\hline 7 & $1 \mathrm{~g}$ & $\mathrm{H}$ & $\mathrm{Cl}$ & $\mathrm{Br}$ & $89 \pm 5.7$ \\
\hline 8 & $1 \mathrm{~h}$ & $\mathrm{H}$ & $\mathrm{Cl}$ & $\mathrm{F}$ & $75 \pm 2.1$ \\
\hline 9 & $1 \mathbf{i}$ & $\mathrm{H}$ & $\mathrm{Cl}$ & $\mathrm{H}$ & $62 \pm 3.2$ \\
\hline 10 & $1 \mathrm{j}$ & $\mathrm{H}$ & $\mathrm{H}$ & $\mathrm{H}$ & $78 \pm 3.5$ \\
\hline
\end{tabular}

${ }^{a}$ Reaction conditions: Alcohol 1a-j (0.1 mmol), T. versicolor laccase (31 U) and TEMPO $(20 \% \mathrm{~mol})$ in a $50 \mathrm{mM} \mathrm{NaOAc}$ buffer $\mathrm{pH} 4.5$ and MTBE $(66 \% \mathrm{v} / \mathrm{v})$ bubbling oxygen at $20^{\circ} \mathrm{C}$ for $24 \mathrm{~h} .{ }^{b}$ Conversion values measured by GC.

Then, chlorohydrin $\mathbf{1 i}$ was also tested as plausible substrate (entry 9). In this case, we observed a $62 \%$ conversion of $\alpha$-chloro ketone $\mathbf{2} \mathbf{i}$ after $24 \mathrm{~h}$ under these oxidative conditions. This result is very important due to the difficulty to achieve this oxidation by other chemical methods, but also because of the versatility of these compounds as intermediates of several high added-value derivatives. Furthermore, when a non-halogenated alcohol such as 1-phenylethanol (1j) was used, a similar conversion compared to the dihalogenated counterparts was achieved (78\%, entry 10), showing that this methodology can work with different types of secondary alcohols. ${ }^{26}$

To emphasize the ability of the laccase/TEMPO system to oxidize secondary alcohols with varying redox strength, we evaluated the relative thermodynamic stability of the halogenated alcohol/ketone pairs $\mathbf{1} \mathbf{a}, \mathbf{i}, \mathbf{j} / \mathbf{2} \mathbf{a}, \mathbf{i}, \mathbf{j}$ with respect to the acetone/2-propanol pair by computing the Gibbs free energy change in aqueous solution $\left(\Delta_{\mathrm{r}} G\right.$, see ESI for more details). ${ }^{19 a}$ The computed $\Delta_{r} G$ energies in $\mathrm{kcal} / \mathrm{mol}$ were $+7.33(\mathbf{1 a}),+4.86(\mathbf{1 i})$, and $+0.61(\mathbf{1 j})$, showing clearly that the dichlorinated alcohol 1a was a weaker reducing agent compared to the mono- $(\mathbf{1 i}$, by $2.5 \mathrm{kcal} / \mathrm{mol})$ or unsubstituted $(\mathbf{1 j}$, by $6.7 \mathrm{kcal} / \mathrm{mol})$ derivatives. Since 1a showed the largest conversion value, it turned out that the differences in the intrinsic redox strength of $\mathbf{1 a , i , j ~ d i d ~ n o t ~}$ affect their oxidation, which is agreement with the accepted ionic mechanism of oxidation mediated by TEMPO. ${ }^{27}$ These results highlight the flexibility of our laccase/TEMPO system.

To demonstrate the mildness and selectivity of this system to oxidize these substrates, different chemical oxidative methods were assessed for the oxidation of 1a (Figure 3). Thus, the laccase was combined with 4-hydroxy-TEMPO (4-OH-TEMPO), but in this case just 5\% conversion was achieved after $24 \mathrm{~h}$. Several mixtures of oxidant(s) and TEMPO were tried in aqueous media such as $\mathrm{NaOCl}$ (9 equiv.), ${ }^{28} \mathrm{NaOCl}(1$ equiv.) $/ \mathrm{KBr}\left(0.2\right.$ equiv.), ${ }^{28} \mathrm{NaOCl}_{2}(1.5$ equiv. $) / \mathrm{NaOCl}\left(0.2\right.$ equiv.), ${ }^{29} \mathrm{CuCl}$ (0.2 equiv.), ${ }^{30} \mathrm{CuBr}_{2}$ (0.2 equiv.), ${ }^{31}$ or iodine (1.5 equiv.), ${ }^{32}$ but negligible or very low conversions were attained. Just when using a stoichiometric amount or an excess of $\mathrm{NaOCl}$, a complex mixture of products formed by benzaldehyde (3a), benzoic acid (4a) and mandelic acid (5a) was detected. This observation correlates with previous reports describing the synthesis of mandelic acid from dihalogenated ketones in aqueous basic medium. ${ }^{33}$

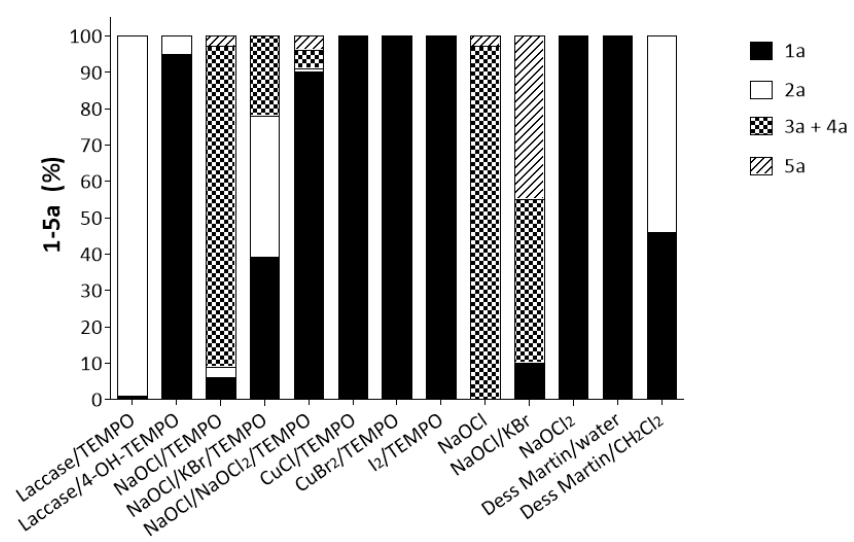

Fig. 3 Oxidation of alcohol 1a into 2a employing different reaction conditions. In some cases, benzaldehyde (3a), benzoic acid (4a), and/or mandelic acid (5a) were obtained as by-products.

The application of $\mathrm{NaOCl}$ or $\mathrm{NaOCl} / \mathrm{KBr}$ led again to a mixture of compounds 3-5a, while $\mathrm{NaOCl}_{2}$ or Dess-Martin periodinane in water did not afford any conversion, recovering the starting material. Only the employment of Dess-Martin periodinane in dichloromethane, ${ }^{8}$ allowed the synthesis of ketone $\mathbf{2 a}$ in $54 \%$ as the sole product at room temperature after $1.5 \mathrm{~h}$. To show the environmental benefits of this system compared to the others, we have performed a simplified environmental impact analysis making use of the $E$-factor concept. ${ }^{34}$ Although it provides a rough estimation of the environmental impact, this value assesses the sustainability of a process. ${ }^{33}$ Thus, we compared $^{34}$ our laccase/TEMPO system with the other three (laccase/4-OH-TEMPO, NaOCl/KBr/TEMPO and Dess-Martin in dichloromethane) which afforded a measurable amount of ketone $\mathbf{2 a}$, obtaining an $E$-factor of 3.5 for the laccase/TEMPO process (excluding solvents) and values higher than 21 for the others (see ESI for details). Also the solvent demand in our method ( $330 \mathrm{~mL} / \mathrm{g}$ product) was much lower in comparison with the other strategies. As a result, these data demonstrate the favorable ecological impact of the laccase/TEMPO pair.

Taken together, we have shown that this methodology making use of a laccase/TEMPO system in a biphasic medium with oxygen as final electron acceptor, is a practical method to get access to $\alpha$ - or $\alpha, \alpha$ dihalogenated ketones via oxidation of the corresponding (di)halohydrins, which in other reaction conditions cannot be selectively obtained. 


\section{COMMUNICATION}

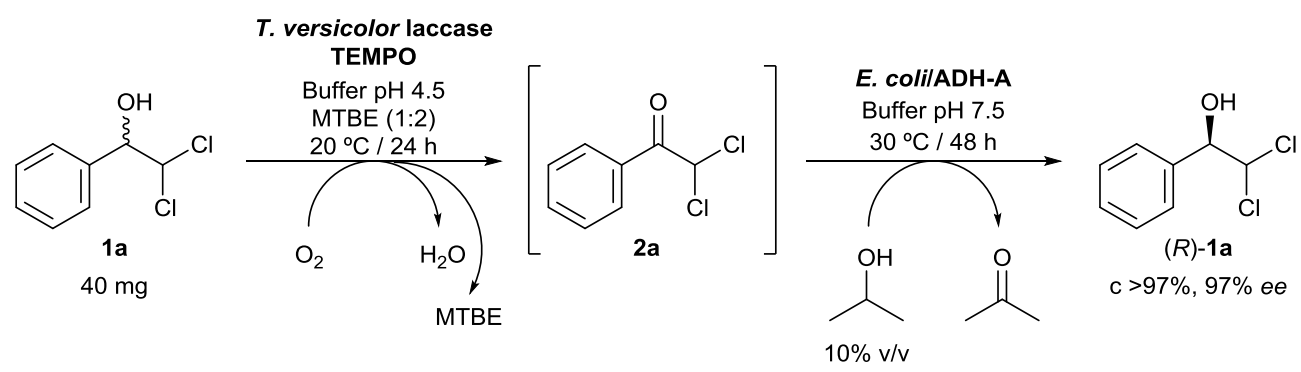

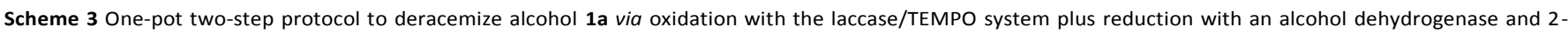
propanol.

Encouraged by these results and as an interesting application of this methodology, we envisaged the deracemization of alcohol 1a through a one-pot two-step chemoenzymatic procedure. To date, the only example for the deracemization of chlorohydrins has been reported by Kroutil and co-workers, ${ }^{10 a}$ combining an alcohol dehydrogenase (for the reduction) with an iridium catalyst (for the oxidation) in a one-pot concurrent system. Unfortunately, the ee values did not exceed $40 \%$ due to undesired interference of both processes. Herein, we propose an alternative strategy starting from the racemic alcohol $\mathbf{1 a}$. In a first step we would achieve the complete oxidation into ketone $\mathbf{2} \mathbf{a}$ with the laccase/TEMPO pair. Subsequently, the addition of a selective ADH would lead to enantioenriched alcohol 1a (Scheme 3).

Hence, this system was successfully applied to deracemize $40 \mathrm{mg}$ of racemic alcohol $\mathbf{2 a}$. After oxidation mediated by $T$. versicolor laccase and TEMPO under the previously optimized conditions, the buffer $\mathrm{pH}$ was adjusted to 7.5 by adding tris(hydroxymethyl)aminomethane (Tris) and a few drops of $\mathrm{HCl}$ (thus inactivating the laccase). Then, alcohol dehydrogenase from Rhodococcus ruber overexpressed in Escherichia coli $(\text { E. coli/ADH-A })^{37}$ and 2-propanol as hydrogen donor $(10 \% \mathrm{v} / \mathrm{v})$ were successively added. After $48 \mathrm{~h}$ at $30{ }^{\circ} \mathrm{C}$, the enantioenriched alcohol $(R)$-1a was obtained in total conversion with $97 \%$ ee. This first example opens the door to sustainable chemoenzymatic deracemization protocols applied to other $\beta$-substituted alcohols that under other chemical conditions cannot be easily obtained.

\section{Conclusions}

In summary, we have shown here an efficient and green method for the selective oxidation of secondary (di)halohydrins into the corresponding halogenated ketones using the laccase from Trametes versicolor and TEMPO pair. Although this process is thermodynamically impeded, the use of this system under aerobic conditions in a biphasic media could provide exclusively the corresponding carbonylic compounds with very high conversions in a clean fashion. This practical method represents a potent alternative to other known oxidative methods which were not able to oxidize these substrates or afforded undesired by-products. Moreover, coupled with a second enzymatic bioreduction, deracemization of a secondary dihalogenated alcohol in a one-pot two-step protocol was feasible, obtaining the enantioenriched $(R)$-alcohol in a very mild and elegant fashion.

Acknowledgments. Financial support from the Spanish Ministerio de Ciencia e Innovación (MICINN-12-CTQ2011-24237), the Principado de Asturias (SV-PA-13-ECOEMP-42 and SV-PA-13-ECOEMP-43) and the Universidad de Oviedo (UNOV-13-EMERG-01 and UNOV-13-EMERG07) is also gratefully acknowledged. I.L. acknowledges MICINN for his research contract under the Ramón y Cajal Program. We thank Prof. Dimas Suárez (University of Oviedo) for $a b$ initio calculations and helpful discussions.

\section{Notes and references}

Departamento de Química Orgánica e Inorgánica, Instituto Universitario de Biotecnología de Asturias, Universidad de Oviedo, C/Julián Clavería 8, 33006 Oviedo, Spain.

Electronic Supplementary Information (ESI) available: [experimental procedures, $a b$ initio and E-factor calculations, substrate characterization, and analytical data are described]. See DOI: $10.1039 /$ c000000x/

1 (a) A. Baiker and T. Mallat, Catal. Sci. Technol., 2013, 3, 267; (b) C. Parmeggiani and F. Cardona, Green Chem., 2012, 14, 547-564; (c) I. W. C. E. Arends and R. A. Sheldon, Modern Oxidation Methods, ed. J.-E. Bäckvall, $2^{\text {nd }}$ ed., Wiley-VCH, Weinheim, 2010, pp. 147-185.

2 Modern Biooxidation. Enzymes, Reactions and Applications, ed. R. D. Schmid and V. B. Urlacher, Wiley-VCH, Weinheim, 2007.

3 (a) Redox Biocatalysis: Fundamentals and Applications, ed. D. Gamenara, G. A. Seoane, P. Saenz-Méndez and P. Domínguez de María, John Wiley \& Sons, Hoboken, 2013; (b) F. Hollmann, K. Bühler and B. Bühler, in Enzyme Catalysis in Organic Synthesis, ed. K. Drauz, H. Gröger and O. May, Wiley-VCH, Weinheim, 2012, pp. 1325-1438.

4 (a) A. Piscitelli, A. Amore and V. Faraco, Curr. Org. Chem., 2012, 16, 2508-2524; (b) P. Giardina, V. Faraco, C. Pezzella, A. Piscitelli, S. 
Vanhulle and G. Sannia, Cell. Mol. Life Sci., 2010, 67, 369-385; (c) S. Witayakran and A. J. Ragauskas, Adv. Synth. Catal., 2009, 351, 11871209; (d) S. Riva, Trends Biotechnol., 2006, 24, 219-226; (e) S. G. Burton, Curr. Org. Chem., 2003, 7, 1317-1331; (f) H. Claus, Arch. Microbiol., 2003, 179, 145-150; $(g)$ E. I. Solomon, U. M. Sundaram and T. E. Machonkin, Chem. Rev., 1996, 96, 2563-2605.

5 (a) N. A. Mohidem and H. B. Mat, Bioresour. Technol., 2012, 114, 472-477; (b) I. Matijosyte, I. W. C. E. Arends, S. de Vries and R. A. Sheldon, J. Mol. Catal. B: Enzym., 2010, 62, 142-148; (c) S. Ncanana, L. Baratto, L. Roncaglia, S. Riva and S. G. Burton, Adv. Synth. Catal., 2007, 349, 1507-1513; (d) M. Zumárraga, T. Bulter, S. Shleev, J. Polaina, A. Martínez-Arias, F. J. Plou, A. Ballesteros and M. Alcalde, Chem. Biol., 2007, 14, 1052-1064; (e) A. Intra, S. Nicotra, S. Riva and B. Danieli, Adv. Synth. Catal., 2005, 347, 973-977; (f) F. d'Acunzo, A. M. Barreca and C. Galli, J. Mol. Catal. B: Enzym., 2004, 31, 25-30; $(g)$ J. Rodakiewicz-Nowak, S. M. Kasture, B. Dudek and J. Haber, J. Mol. Catal. B: Enzym., 2000, 11, 1-11.

6 See, for instance: (a) P. Könst, S. Kara, S. Kochius, D. Holtmann, I. W. C. E. Arends, R. Ludwig and F. Hollmann, ChemCatChem, 2013, 5, 3027-3032; (b) T. Kudanga, G. S. Nyanhongo, G. M. Guebitz and S. Burton, Enzyme Microb. Technol., 2011, 48, 195-208; (c) O. V. Morozova, G. P. Shumakovich, S. V. Shleev and Y. I. Yaropolov, Appl. Biochem. Microbiol., 2007, 43, 523-535; (d) A. Wells, M. Teria and T. Eve, Biochem. Soc. Trans., 2006, 34, 304-308; (e) M. Fabbrini, C. Galli and P. Gentili, J. Mol. Catal. B: Enzym., 2002, 16, 231-240.

7 (a) A. Díaz-Rodríguez, I. Lavandera, S. Kanbak-Aksu, R. A. Sheldon, V. Gotor and V. Gotor-Fernández, Adv. Synth. Catal., 2012, 354, 34053408; (b) I. W. C. E. Arends, Y.-X. Li, R. Ausan and R. A. Sheldon, Tetrahedron, 2006, 62, 6659-6665; (c) M. Marzorati, B. Danieli, D. Haltrich and S. Riva, Green. Chem., 2005, 7, 310-315; (d) M. Fabbrini, C. Galli, P. Gentili and D. Macchitella, Tetrahedron Lett., 2001, 42, 7551-7553.

8 (a) V. Pace and W. Holzer, Tetrahedron Lett., 2012, 53, 5106-5109; (b) V. Pace, A. Cortés Cabrera, M. Fernández, J. V. Sinisterra and A. R. Alcántara, Synthesis, 2010, 3545-3555.

9 (a) A. Träff, K. Bogár, M. Warner and J.-E. Bäckvall, Org. Lett., 2008, 10, 4807-4810; (b) B. Martín-Matute, M. Edin, K. Bogár, F. B. Kaynak and J.-E. Bäckvall, J. Am. Chem. Soc., 2005, 127, 8817-8825; (c) J. H. Choi, Y. K. Choi, Y. H. Kim, E. S. Park, E. J. Kim, M.-J. Kim and J. Park, J. Org. Chem., 2004, 69, 1972-1977; (d) O. Pàmies and J.-E. Bäckvall, J. Org. Chem., 2002, 67, 9006-9010.

10 (a) F. G. Mutti, A. Orthaber, J. H. Schrittwieser, J. G. de Vries, R. Pietschnig and W. Kroutil, Chem. Commun., 2010, 46, 8046-8048; (b) T. Jerphagnon, A. J. A. Gayet, F. Berthiol, V. Ritleng, N. Mršić, A. Meetsma, M. Pfeffer, A. J. Minnaard, B. L. Feringa and J. G. de Vries, Chem.-Eur. J., 2009, 15, 12780-12790; (c) R. M. Haak, F. Berthiol, T. Jerphagnon, A. J. A. Gayet, C. Tarabiono, C. P. Postema, V. Ritleng, M. Pfeffer, D. B. Janssen, A. J. Minnaard, B. L. Feringa and J. G. de Vries, J. Am. Chem. Soc., 2008, 130, 13508-13509.

11 T. M. Poessl, B. Kosjek, U. Ellmer, C. C. Gruber, K. Edegger, K. Faber, P. Hildebrandt, U. T. Bornscheuer and W. Kroutil, Adv. Synth. Catal., 2005, 347, 1827-1834.

12 B. Seisser, I. Lavandera, K. Faber, J. H. Lutje Spelberg and W. Kroutil, Adv. Synth. Catal., 2007, 349, 1399-1404.

13 F. R. Bisogno, A. Cuetos, A. A. Orden, M. Kurina-Sanz, I. Lavandera and V. Gotor, Adv. Synth. Catal., 2010, 352, 1657-1661.
14 E. B. Ayres and C. R. Hauser, J. Am. Chem. Soc., 1943, 65, 1095-1096.

15 (a) S. Asghari and A. K. Habibi, Tetrahedron, 2012, 68, 8890-8898; (b) R. Zimmer, J. Angermann, U. Hain, F. Hiller and H. U. Reissig, Synthesis, 1997, 1467-1474; (c) A. Le Rouzic, M. Duclos and H. Patin, Bull. Soc. Chim. Fr., 1991, 952-961.

16 J. Limanto, R. A. Desmond, D. R. Gauthier, Jr., P. N. Devine, R. A. Reamer and R. P. Volante, Org. Lett., 2003, 5, 2271-2274.

17 (a) C. Peppe and R. P. das Chagas, J. Organomet. Chem., 2006, 691, 5856-5860; (b) J. M. Concellón, H. Rodríguez-Solla, C. Concellón and P. Díaz, Synlett, 2006, 837-840.

18 (a) S. S. van Berkel, S. Brauch, L. Gabriel, M. Henze, S. Stark, D. Vasilev, L. A. Wessjohann, M. Abbas and B. Westermann, Angew. Chem., Int. Ed., 2012, 51, 5343-5346; (b) M. S. Raghavendra and Y. Lam, Tetrahedron Lett., 2004, 45, 6129-6132; (c) K. Sakai, N. Hida and K. Kondo, Bull. Chem. Soc. Jpn., 1986, 59, 179-183.

19 (a) F. R. Bisogno, E. García-Urdiales, H. Valdés, I. Lavandera, W. Kroutil, D. Suárez and V. Gotor, Chem.-Eur. J., 2010, 16, 1101211019; (b) I. Lavandera, A. Kern, V. Resch, B. Ferreira-Silva, A. Glieder, W. M. F. Fabian, S. de Wildeman and W. Kroutil, Org. Lett., 2008, 10, 2155-2158.

20 (a) A. M. Barreca, M. Fabbrini, C. Galli, P. Gentilli and S. Ljunggren, J. Mol. Catal. B: Enzym., 2003, 26, 105-110; (b) E. Srebotnik and K. E. Hammel, J. Biotechnol., 2000, 81, 179-188; (c) H. Xu, Y.-Z. Lai, D. Slomczynski, J. P. Nakas and S. W. Tanenbaum, Biotechnol. Lett., 1997, 19, 957-960.

21 The blank experiments using just the laccase or TEMPO $(20 \% \mathrm{~mol})$, did not afford any conversion.

22 (a) G. Cantarella, F. d'Acunzo and C. Galli, Biotechnol. Bioeng., 2003, 82, 395-398; (b) F. d'Acunzo, C. Galli and B. Masci, Eur. J. Biochem., 2002, 269, 5330-5335; (c) J. Rodakiewicz-Nowak, Top. Catal., 2000, 11-12, 419-434.

23 K. Alfonsi, J. Colberg, P. J. Dunn, T. Fevig, S. Jennings, T. A. Johnson, H. P. Kleine, C. Knight, M. A. Nagy, D. A. Perry and M. Stefaniak, Green Chem., 2008, 10, 31-36.

24 Another indication that substrate solubilization played an important role in this oxidative reaction was the fact that when alcohol 1a (a crystal solid) was crushed into very tiny pieces, the conversion in plain $\mathrm{NaOAc}$ buffer ( $50 \mathrm{mM}, \mathrm{pH} 4.5$ ) increased from less than $10 \%$ to $47 \%$ after $24 \mathrm{~h}$ at $20^{\circ} \mathrm{C}$.

25 I. W. C. E. Ardens, Y. Li and R. A. Sheldon, Biocatal. Biotransform., 2006, 24, 443-448.

26 Further experiments oxidizing mixtures of dichlorinated alcohol 1a with monohalogenated derivative $\mathbf{1} \mathbf{i}$ or unsubstituted compound $\mathbf{1} \mathbf{j}$ afforded, as expected, mixtures of the corresponding ketones in similar ratios (see ESI for more details).

27. (a) S. A. Tromp, I. Matijošytè, R. A. Sheldon, I. W. C. E. Arends, G. Mul, M. T. Kreutzer, J. A. Moulijn and S. de Vries, ChemCatChem, 2010, 2, 827-833; (b) F. D'Acunzo, P. Baiocco, M. Fabbrini, C. Galli and P. Gentili, Eur. J. Org. Chem., 2002, 4195-4201.

28 P. L. Anelli, S. Banfi, F. Montanari and S. Quici, J. Org. Chem., 1989, 54, 2970-2972.

29 M. Zhao, J. Li, E. Mano, Z. Song, D. M. Tschaen, E. J. J. Grabowski and P. J. Reider, J. Org. Chem., 1999, 64, 2564-2566.

30 M. F. Semmelhack, C. R. Schmid, D. A. Cortés and C. S. Chou, J. Am. Chem. Soc., 1984, 106, 3374-3376.

31 T. Miyazawa and T. Endo, J. Mol. Catal., 1985, 32, 357-360. 
32 R. A. Miller and R. S. Hoerrner, Org. Lett., 2003, 5, 285-287.

33 J. G. Aston, J. D. Newkirk, J. Dorsky and D. M. Jenkins, J. Am. Chem. Soc., 1942, 64, 1413-1416.

34 (a) R. A. Sheldon, Chem. Ind., 1992, 903-906; (b) R. A. Sheldon, Green Chem., 2007, 9, 1273-1283.

35 A recent example can be found in: J. H. Schrittwieser, F. Coccia, S. Kara, B. Grischek, W. Kroutil, N. d'Alessandro and F. Hollmann, Green Chem., 2013, 15, 3318-3331.

36 (a) M. Eissen and J. O. Metzger, Chem.-Eur. J., 2002, 8, 3580-3585; (b) EATOS: Environmental Assessment Tool for Organic Syntheses, http://www.metzger.chemie.uni-oldenburg.de/eatos/english.htm, Accessed: 05.02.2014.

37 K. Edegger, C. C. Gruber, T. M. Poessl, S. R. Wallner, I. Lavandera, K. Faber, F. Niehaus, J. Eck, R. Oehrlein, A. Hafner and W. Kroutil, Chem. Commun., 2006, 2402-2404. 